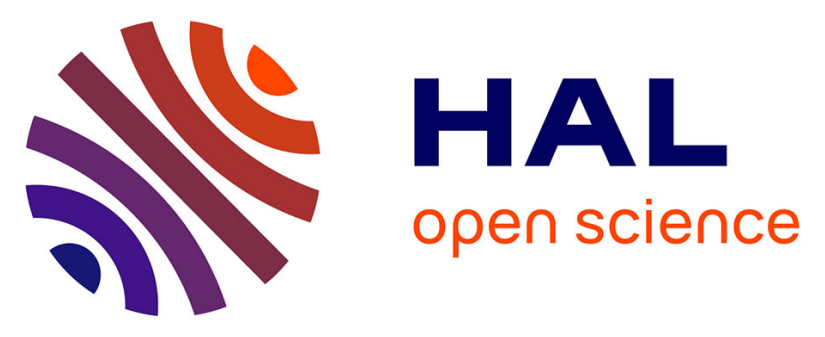

\title{
Modification of the carrier mobility of conducting PF-EP polymer by formation of their composites with thiophene derivatives
}

Sergey Tokarev, Yury Fedorov, Anna Moiseeva, Gedaminas Jonusauskas, Dmitry Lypenko, Alexey Aleksandrov, Alexey Tameev, Eugene Maltsev, Galina Nosova, Elena Zhukova, et al.

\section{To cite this version:}

Sergey Tokarev, Yury Fedorov, Anna Moiseeva, Gedaminas Jonusauskas, Dmitry Lypenko, et al.. Modification of the carrier mobility of conducting PF-EP polymer by formation of their composites with thiophene derivatives. Organic Electronics, 2019, pp.105586. 10.1016/j.orgel.2019.105586 . hal02413060

\author{
HAL Id: hal-02413060 \\ https://hal.science/hal-02413060
}

Submitted on 30 Dec 2020

HAL is a multi-disciplinary open access archive for the deposit and dissemination of scientific research documents, whether they are published or not. The documents may come from teaching and research institutions in France or abroad, or from public or private research centers.
L'archive ouverte pluridisciplinaire HAL, est destinée au dépôt et à la diffusion de documents scientifiques de niveau recherche, publiés ou non, émanant des établissements d'enseignement et de recherche français ou étrangers, des laboratoires publics ou privés. 


\title{
Modification of the carrier mobility of conducting PF-EP polymer by formation of their composites with thiophene derivatives
}

\author{
Sergey D. Tokarev ${ }^{\mathrm{a}, \mathrm{b}}$, Yury V. Fedorov ${ }^{\mathrm{b}}$, Anna A. Moiseeva ${ }^{\mathrm{a}}$, Gediminas Jonusauskas ${ }^{\mathrm{c}}$, \\ Dmitry A. Lypenko ${ }^{\mathrm{d}}$, Alexey E. Aleksandrov ${ }^{\mathrm{d}}$, Alexey R. Tameev ${ }^{\mathrm{d}}$, Eugene I. Maltsev ${ }^{\mathrm{d}}$, \\ Galina I. Nosova ${ }^{\mathrm{e}}$, Elena V. Zhukova ${ }^{\mathrm{e}}$, Olga A. Fedorova ${ }^{\mathrm{a}, \mathrm{b}, *}$ \\ ${ }^{a}$ Department of Chemistry, M. V. Lomonosov Moscow State University, Leninskie Gory, 119992, Moscow, Russia \\ ${ }^{\mathrm{b}}$ A. N. Nesmeyanov Institute of Organoelement Compounds, Russian Academy of Sciences, 28 Vavilova str., 119991, Moscow, Russia \\ ${ }^{\mathrm{c}}$ Laboratoire Ondes et Matiere d'Aquitaine, UMR CNRS 5798, CNRS, University of Bordeaux, 351 Cours de la Liberation, 33405, Talence, France \\ ${ }^{\mathrm{d}}$ A.N. Frumkin Institute of Physical Chemistry and Electrochemistry, Russian Academy of Sciences, Leninsky Prosp. 31, bld.4, 119071, Moscow, Russia \\ ${ }^{\mathrm{e}}$ Institute of macromolecular compounds, Russian Academy of Sciences, Bolshoy pr. 31, 199004, Saint-Petersburg, Russia
}

\begin{abstract}
A B S T R A C T
In the paper we present synthesis and characterization of new donor-acceptor thiophene derivatives (TDs) containing vinylbenzo[d]thiazole, vinylpyridine and $1 \mathrm{H}$-imidazo[4,5- $f][1,10]$ phenanthroline residues. Using CELIV method, electron and hole mobility have been studied in the polymer layers based on poly [9,9-bis(6diethoxyl-phosphorylhexyl)fluorine] (PF-EP) doped with the TDs. Polymer light-emitting diodes (PLEDs) containing newly synthesized polyfluorene (PF) as emitting layers and PF-EP/TD composites as electron transporting layers show higher brightness at $15 \mathrm{~V}$ as compared with TD free PF-EP.
\end{abstract}

\section{Introduction}

Semiconducting polymers have several advantages such as mechanical flexibility, easy processing and transparency which help in the fabrication of cheaper flexible electronic devices [1]. The polymers has been recently applied for the production of various cheap OLEDs [2], transistors, energy storage elements [3], solar cells [4], chemical/biosensors [5], thermoelectric [6] and rechargeable batteries [7]. However, typical charge carrier mobility in these materials is low. Therefore, increased attention was directed to study hybrid assemblies based on semiconducting polymers with compounds like non-conducting macromolecules, metals, metal oxides/chalcogenides, carbonaceous and some other inorganic materials [8-12]. However, the success of these attempts has remained limited. Information on the advantageous use of small molecules as effective dopants in semiconducting polymer composites is still scarce.

Donor-acceptor (D-A) $\pi$-conjugated organic molecules are widely investigated as active materials in organic solar cells [13-20] for they are able to reduce the band gap [13,14,21]. Moreover, they were shown to be able to reach higher power conversion efficiency (PCE) and ease of device fabrication [22]. Another possible field of application is their use as active charge transport layers in organic flexible electronics [23,24]. Structure-properties correlations have been established for organic p-type, n-type and ambipolar molecules. In particular, organic semiconductors that exhibit both electron and hole transport are key components for the manufacture of complementary metal-oxide semiconductor (CMOS), digital integrated circuits [25-28] and organic light-emitting transistor (OLETs) devices [29-31].

Thiophene and its derivatives possess important electroluminescent characteristics. They are used as energy transfer and light-harvesting systems in various optical and electronic devices [32], as well as sensors and fluorescent markers [33-36]. Oligomeric thiophenes usually have good solubility and can be easily modified to fit various applications. For example, electron-donating (ED) and electron-withdrawing (EW) groups are used to tune the band gap and electron mobility of the oligomers. The intermolecular interactions and thin film morphology of these compounds change dramatically when ED or EW substituents are introduced [37]. Moreover, their position in oligomers is able to make different effects on the electronic properties [38].

Here, we synthesized and studied a series of mono- (1a-d) and bithiophene-containing derivatives (2a-d) (Scheme 1) constructed as donor-acceptor $\pi$-conjugated (D- $\pi-\mathrm{A})$ systems for doping polymer

\footnotetext{
* Corresponding author. A. N. Nesmeyanov Institute of Organoelement Compounds, Russian Academy of Sciences, 28 Vavilova str., 119991, Moscow, Russia E-mail address: fedorova@ineos.ac.ru (O.A. Fedorova).
} 
matrix based on PF-EP. The synthesis of the polymer was given in Ref. [39]. Also the aim was to analyze the correlation between their structure, photophysical, electrochemical and charge transport properties in PE-EP composites. Earlier, the 2- or 3-styrylthiophene derivatives were used as initial reagents for obtaining polymers [40] and new near infrared compounds in bioimaging [41]. They were successfully applied in the analysis of TD excitation states [26,42] as well as efficient EL components [43].

\section{Experimental}

\subsection{General}

All reagents and solvents were purchased from Acros, Aldrich, Merck and used without additional purification. Spectroscopic grade acetonitrile (MeCN), DMSO, ethyl acetate were used for spectroscopic and fluorimetric measurements.

${ }^{1} \mathrm{H}$ and ${ }^{13} \mathrm{C}$ (APT method) NMR spectra were recorded on a Bruker AVANCE-400 and Avance-500 spectrometers. The chemical shifts and spin-spin coupling constants were determined with accuracy of 0.01 ppm and $0.1 \mathrm{~Hz}$, respectively.

ESI mass spectra (ESI-MS) of $\mathbf{1} \mathbf{a}-\mathbf{d}$ and $\mathbf{2 a} \mathbf{a} \mathbf{b}$ were acquired on a Finnigan LCQ Advantage tandem dynamic mass spectrometer (USA) equipped with a mass analyzer with an octapole ionic trap, a MS Surveyor pump, a Surveyor autosampler, a Schmidlin-Lab nitrogen generator (Germany), and a system of data collection and processing using the $\mathrm{X}$ Calibur program, version 1.3 (Finnigan). The mass spectra were measured in the positive ion mode. Samples in MeCN were injected directly into the source at flow rate $50 \mu \mathrm{L} \cdot \mathrm{min}^{1}$ through a Reodyne injector with a loop of $20 \mu \mathrm{L}$. The temperature of the transfer capillary was $150 \mathrm{C}$, and the electrospray needle was held at potential $4.0 \mathrm{kV}$.

The electron impact mass spectra of $\mathbf{1 a - d , ~ 2 a , b}$ were recorded on a Finnigan Polaris $\mathrm{Q}$ instrument. The energy of ionizing electrons was 70 eV. $1 \%$ solutions of compounds in $\mathrm{CH}_{2} \mathrm{Cl}_{2}$ or $\mathrm{CHCl}_{3}(0.2 \mu \mathrm{l})$ were loaded into quartz micro-ampoules, which were inserted into the heated tip of the direct input rod. Thermomass spectrograms were filmed in the process of stepped (after $50 \mathrm{C}$ ) heating of ampoules from 50 to $150 \mathrm{C}$.
Before heating the samples in the same temperature range, the thermomass spectrogram of the empty ampoule was usually taken to confirm an absence of any impurities in the ampoule and rod.

LDI-TOF mass spectra of $\mathbf{2 c}$ and $2 \mathrm{~d}$ were collected with Bruker Autoflex II instrument, samples were irradiated with nitrogen laser (1 $337 \mathrm{~nm}$ ). Isotopic patterns were calculated with Isotope Viewer 2000.

Elemental analysis was performed on a Carlo Erba 1108 elemental analyzer.

The synthesis of the copolymer PF (Scheme 2) was carried out in a Discover LabMate single-mode microwave reactor (CEM Corporation, United States) at a radiation frequency of $2.45 \mathrm{GHz}$ and a maximum generator power of $300 \mathrm{~W}$. The temperature of synthesis was controlled using an infrared sensor placed under the reaction vessel. The reaction parameters (temperature, power, time, stirring rate) were set manually. The molecular-mass characteristics of the copolymer were determined using size-exclusion liquid chromatography at $40 \mathrm{C}$ on an Agilent Technologies 1260 Infinity chromatograph equipped with a refractometric detector. THF served as a mobile phase, molecular-mass characteristics were calculated using PS standards.

\subsection{Synthesis}

[2,2'-Bithiophene]-5,5'-dicarbaldehyde [44], 2,2'-bithiophene-5-carbaldehyde [44], 2,3-dimethylbenzo[d]thiazol-3-ium perchlorate [45], 7-methylbenzo[1,2-d:3,4-d']bis(thiazole)-2-amine [46] and 5, 5'-bis(1H-imidazo[4,5-f] [1,10]phenanthrolin-2-yl)-2,2'-bithiophene (2c) [47] were prepared by using known synthetic procedures.

\subsubsection{Synthesis of (E)-2-(2-([2,2'-bithiophen]-5-yl)vinyl)benzo[d] thiazole (1a)}

Solution of 2,2'-bithiophen-5-carbaldehyde (1.55 mmol, $300 \mathrm{mg}$ ) and 2-methylbenzo[d]thiazole ( $1.55 \mathrm{mmol}, 196 \mu \mathrm{l})$ in $7 \mathrm{ml}$ of DMSO was stirred for $10 \mathrm{~min}$, then $18.75 \mathrm{ml}$ of $50 \% \mathrm{KOH}$ water solution was added and the mixture was left without stirring for 2 days in the dark. After complete reaction the precipitate was filtered off, washed with water
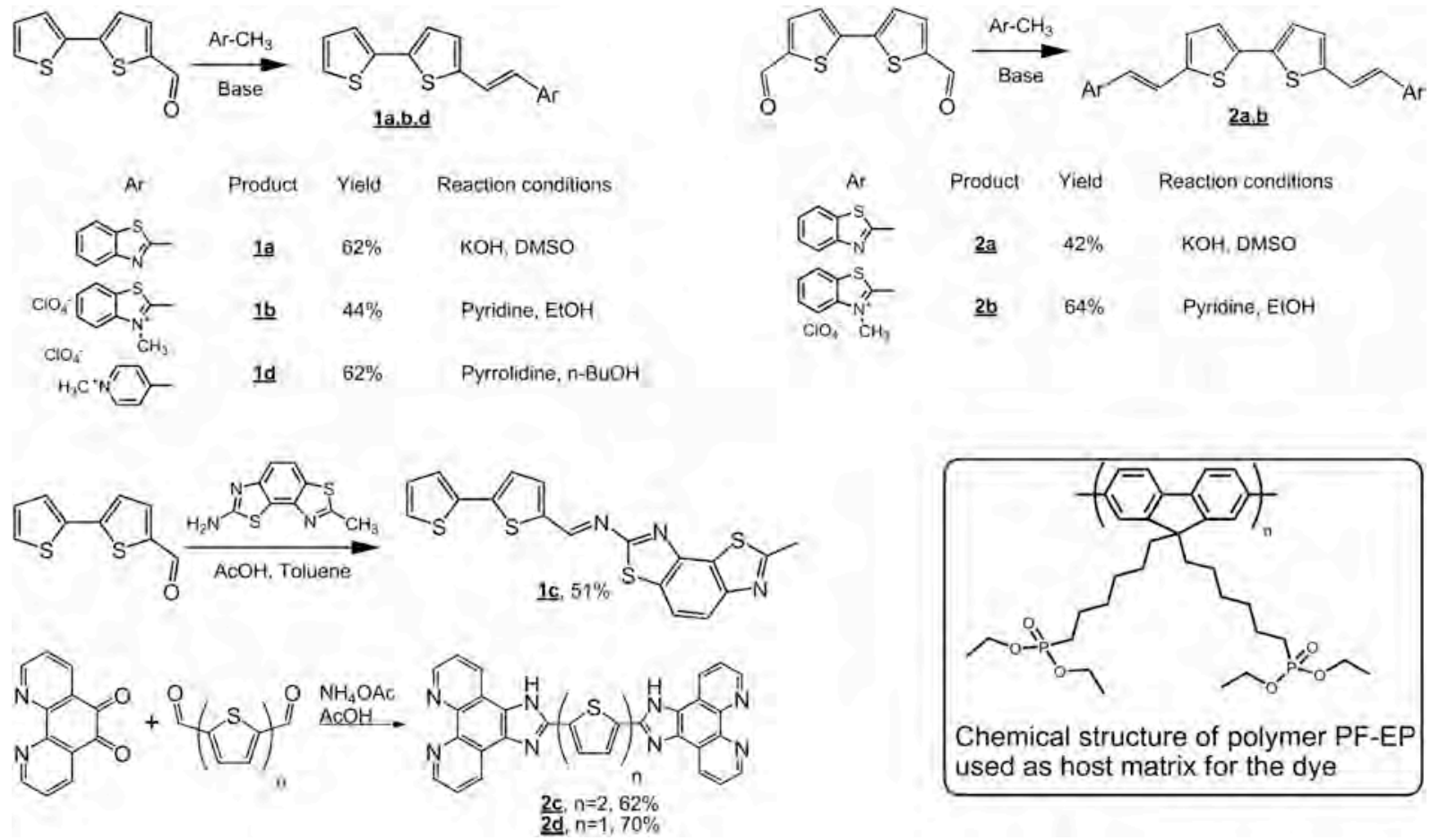

Scheme 1. Synthesis of dyes 1a-d, 2a-d, and structure of polymer host matrix. 

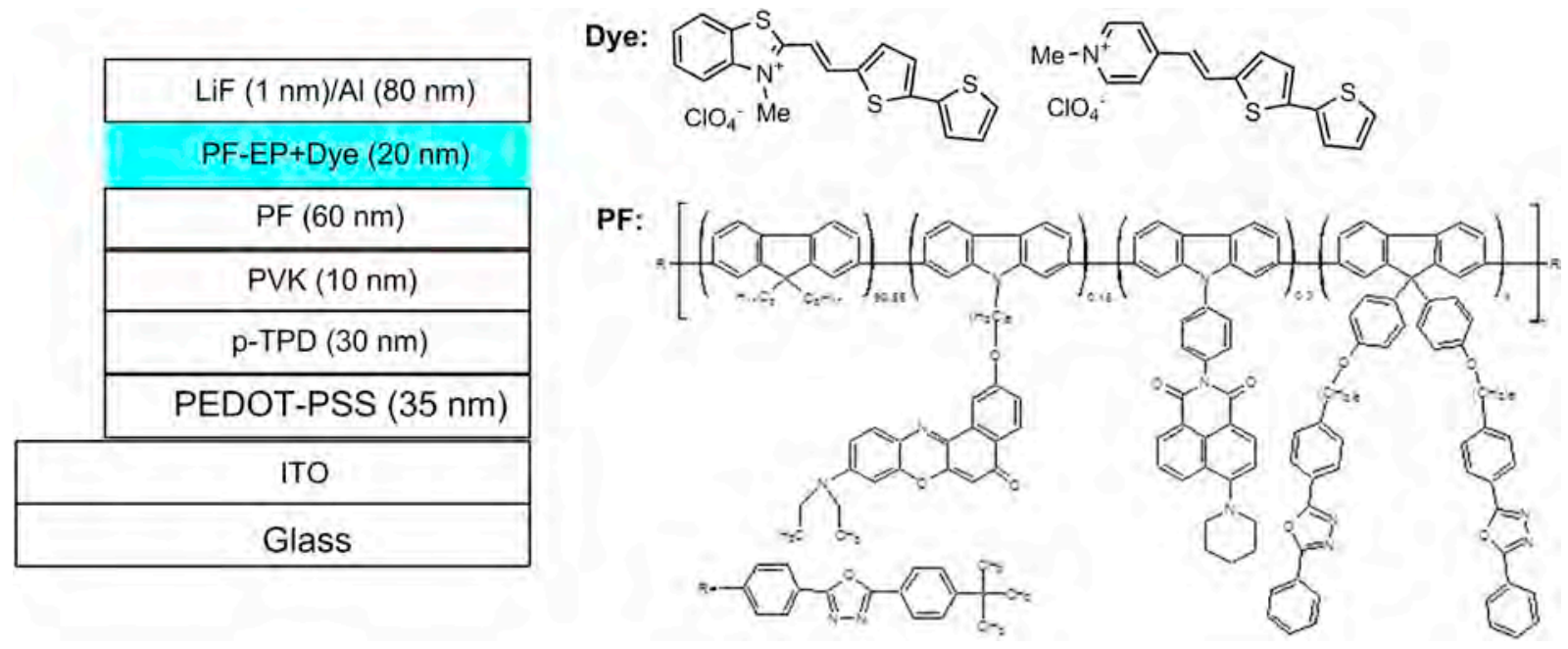

Scheme 2. Switch structure of OLED based on PF-EP Dye composition.

and methanol and dried on a filter. The orange powder on a filter was a pure product (0.91 mmol, $297 \mathrm{mg}$, yield $62 \%) .{ }^{1} \mathrm{H} \mathrm{NMR}\left(\mathrm{CDCl}_{3} ; \delta ; \mathrm{ppm}\right.$, J/Hz): 7.04 (dd, $1 \mathrm{H},{ }^{3} \mathrm{~J} \quad 3.8,{ }^{3} \mathrm{~J} \quad$ 4.9) $\mathrm{H}(4) ; 7.12-7.18$ (m, 3H) H(a,b), $\mathrm{H}\left(3,3^{\prime}, 4^{\prime}\right) ; 7.25$ (d, $\left.1 \mathrm{H},{ }^{3} \mathrm{~J} \quad 3.4\right) \mathrm{H}\left(3,3^{\prime}, 4^{\prime}\right) ; 7.27$ (d, $\left.1 \mathrm{H},{ }^{3} \mathrm{~J} \quad 4.9\right) \mathrm{H}(5)$;

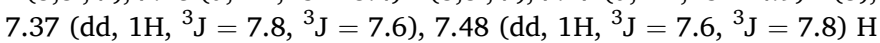
$\left(6^{\prime \prime}, 7^{\prime \prime}\right) ; 7.61-7.65$ (d, $1 \mathrm{~h},{ }^{3} \mathrm{~J} \quad$ 15.9) H(a,b); 7.85 (d, 1H, $\left.{ }^{3} \mathrm{~J} \quad 7.8\right), 8.00$ (d, $\left.1 \mathrm{H},{ }^{3} \mathrm{~J} \quad 7.8\right) \mathrm{H}\left(5^{\prime \prime}, 8^{\prime \prime}\right) .{ }^{13} \mathrm{C}$ NMR $\left(\mathrm{CDCl}_{3} ; \delta ; \mathrm{ppm}\right): 120.62 ; 121.47$; 122.76 ; 124.39; 124.53; 125.26; 125.33; 126.40; 128.04; 130.06; $130.44(\mathrm{CH}) ; 119.28 ; 134.20 ; 136.85 ; 139.34 ; 141.96 ; 166.35$ (C). Calculated for $\mathrm{C}_{17} \mathrm{H}_{11} \mathrm{NS}_{3}(\%)$ : C, 62.73; H, 3.41; N, 4.30; found (\%): C, $62.51 \mathrm{H}, 3.67$; N, 4.09. MS, $\mathrm{m} / z$ (\%): calcd. 325.5; found 324.592 [M$\mathrm{H}^{-}(100)$.

\subsubsection{Synthesis of (E)-2-(2-([2,2'-bithiophen]-5-yl)vinyl)-3-methylbenzo} [d] thiazol-3-ium perchlorate (1b)

Solution of 2,2'-bithiophene-5-carbaldehyde $(0.77 \mathrm{mmol}, 150 \mathrm{mg})$, 2,3-dimethylbenzo[d]thiazol-3-ium perchlorate $(0.77 \mathrm{mmol}, 203 \mathrm{mg}$ ) and $750 \mu \mathrm{l}$ of pyridine in $7 \mathrm{ml}$ of ethanol was refluxed for $30 \mathrm{~h}$ in darkness. Reaction mixture was evaporated dry on a rotary evaporator and $10 \mathrm{ml}$ of methanol was added. Mixture was refluxed for $1 \mathrm{~min}$ to dissolve starting reagents and impurities. After filtering on a glass porous filter the pure product was obtained as a dark-brown precipitate (0.34 mmol, $149 \mathrm{mg}$, yield 44\%). ${ }^{1} \mathrm{H}$ NMR $\left(\mathrm{CD}_{3} \mathrm{CN} ; \delta ; \mathrm{ppm}, \mathrm{J} / \mathrm{Hz}\right): 4.18$ $\begin{array}{lll}(\mathrm{s}, 3 \mathrm{H}) \mathrm{CH}_{3} ; 7.15 \text { (dd, } 1 \mathrm{H},{ }^{3} \mathrm{~J} & 5.0,{ }^{3} \mathrm{~J} & 3.7) \mathrm{H}(4) ; 7.29-7.33\left(\mathrm{~d}, 1 \mathrm{H},{ }^{3} \mathrm{~J}\right.\end{array}$ 15.5) H(a,b); 7.40 (d, $\left.1 \mathrm{H},{ }^{3} \mathrm{~J} \quad 4.0\right), 7.48\left(\mathrm{~d}, 1 \mathrm{H},{ }^{3} \mathrm{~J} \quad 3.7\right), 7.67(\mathrm{~d}, 1 \mathrm{H}$,

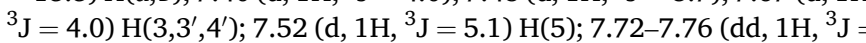
$\left.7.9,{ }^{3} \mathrm{~J} \quad 8.4\right), 7.82-7.86$ (dd, $\left.1 \mathrm{H},{ }^{3} \mathrm{~J} \quad 8.5,{ }^{3} \mathrm{~J} \quad 8.4\right) \mathrm{H}\left(6^{\prime \prime}, 7^{\prime \prime}\right) ; 7.97$ (d, $\left.1 \mathrm{H},{ }^{3} \mathrm{~J} \quad 8.5\right) \mathrm{H}\left(5^{\prime \prime}, 8^{\prime \prime}\right) ; 8.16-8.22(\mathrm{~m}, 2 \mathrm{H}) \mathrm{H}\left(5^{\prime \prime}, 8^{\prime \prime}\right), \mathrm{H}(\mathrm{a}, \mathrm{b}) .{ }^{13} \mathrm{C}$ NMR ( $\mathrm{CD}_{3} \mathrm{CN} ; \delta$; ppm): $35.62\left(\mathrm{CH}_{3}\right) ; 109.83 ; 115.84 ; 123.31 ; 125.28 ; 126.07$; $127.47 ; 128.19 ; 128.46 ; 129.26 ; 136.94 ; 140.83(\mathrm{CH}) ; 127.33 ; 135.34$; $137.21 ; 141.77 ; 144.93$ 170.97(C). Calculated for $\mathrm{C}_{18} \mathrm{H}_{14} \mathrm{ClNO}_{4} \mathrm{~S}_{3}(\%)$ : C, 49.14; H, 3.21; N, 3.18; found (\%): C, $48.93 \mathrm{H}, 3.42$; N, 3.01. ESI-MS in $\mathrm{MeCN}, \mathrm{m} / \mathrm{z}$ : calcd. 340.03; found 340.071 [M] (100).

\subsubsection{Synthesis of (E)-N-([2,2'-bithiophen]-5-ylmethylene)-2-}

methylbenzo[1,2-d:3,4-d']bis(thiazole)-7-amine (1c)

7-Methylbenzo[1,2-d:3,4-d']bis(thiazole)-2-amine (0.9 mmol, 200 $\mathrm{mg}$ ) and 2,2'-bithiophene-5-carbaldehyde (0.9 mmol, $176 \mathrm{mg}$ ) were separately dissolved in toluene, in case of the amine a little heating was required. Toluene solutions were mixed and $3 \mathrm{ml}$ of glacial acetic acid was added. Reaction solution was refluxed for $30 \mathrm{~h}$, after complete reaction solvent was removed on a rotary evaporator, $10 \mathrm{ml}$ of ethanol were added and mixture was refluxed for 5-10 min. The precipitate formed was filtered on a glass porous filter and washed with ethanol. The pure product was obtained by flash chromatography $\left(\mathrm{SiO}_{2}\right.$, benzene: acetonitrile 12:1), $0.459 \mathrm{mmol}, 182 \mathrm{mg}$, yield $51 \%$. ${ }^{1} \mathrm{H}$ NMR (DMSO-d $d_{6} ; \delta$; ppm, J/Hz): 2.88 (s, 3H) $\mathrm{CH}_{3} ; 7.19$ (dd, $1 \mathrm{H},{ }^{3} \mathrm{~J} \quad 5.0,{ }^{3} \mathrm{~J}$ 3.7) $\mathrm{H}(4) ; 7.55\left(\mathrm{~d}, 1 \mathrm{H},{ }^{3} \mathrm{~J} \quad 3.97\right), 7.61\left(\mathrm{~d}, 1 \mathrm{H},{ }^{3} \mathrm{~J} \quad 3.6\right), 7.99\left(\mathrm{~d}, 1 \mathrm{H},{ }^{3} \mathrm{~J}\right.$ 3.9) $\mathrm{H}\left(3,3^{\prime}, 4^{\prime}\right) ; 7.71$ (d, $1 \mathrm{H},{ }^{3} \mathrm{~J} \quad$ 5.1) $\mathrm{H}(5) ; 7.93$ (d, $\left.1 \mathrm{H},{ }^{3} \mathrm{~J} \quad 8.7\right), 8.15$ $\left(\mathrm{d}, 1 \mathrm{H},{ }^{3} \mathrm{~J} \quad 8.6\right) \mathrm{H}\left(7^{\prime \prime}, 8^{\prime \prime}\right) .{ }^{13} \mathrm{C}$ NMR (DMSO-d 6 ; $\delta$ ppm): $19.83\left(\mathrm{CH}_{3}\right)$; $119.24 ; 120.23$; $125.54 ; 126.84 ; 128.30 ; 128.95 ; 139.68 ; 159.14$ (CH); $126.34 ; 131.54 ; 135.55 ; 138.83 ; 144.85 ; 146.07 ; 150.54 ; 169.93$; 170.37 (C). Calculated for $\mathrm{C}_{18} \mathrm{H}_{11} \mathrm{~N}_{3} \mathrm{~S}_{4}$ (\%): C, 54.38; H, 2.79; N, 10.57; found (\%): C, $54.18 \mathrm{H}, 2.93$; N, 10.30. MS, $m / z$ (\%): calcd. 397.5; found $396.516[\mathrm{M}-\mathrm{H}]^{-}(100)$.

\subsubsection{Synthesis of (E)-4-(2-([2,2'-bithiophen]-5-yl)vinyl)-1- methylpyridin-1-ium perchlorate (1d)}

Mixture of 2,2'-bithiophen-5-carbaldehyde (1.97 mmol, $383 \mathrm{mg}$ ), 1,4-dimethylpyridin-1-ium perchlorate (1.97 mmol, $410 \mathrm{mg}$ ), pyrrolidine $(1.97 \mathrm{mmol}, 140 \mu \mathrm{l})$ in $10 \mathrm{ml}$ of $\mathrm{n}$-butanol was refluxed for $30 \mathrm{~min}$ in darkness. The precipitate formed was filtered on a glass porous filter, washed with methanol, dried on a filter and recrystallized from acetonitrile/benzene mixture. The pure product was obtained as an orange powder (1.22 mmol, $468 \mathrm{mg}$, yield $62 \%) .{ }^{1} \mathrm{H} \mathrm{NMR}\left(\mathrm{CD}_{3} \mathrm{CN} ; \delta\right.$; ppm, J/ $\mathrm{Hz}$ ): 4.16 (s, 3H) $\mathrm{CH}_{3} ; 6.99-7.03\left(\mathrm{~d}, 1 \mathrm{H},{ }^{3} \mathrm{~J}\right.$ 16.0) H(a,b); 7.11 (dd, $1 \mathrm{H}$, $\left.{ }^{3} \mathrm{~J} \quad 3.7,{ }^{3} \mathrm{~J} \quad 5.1\right) \mathrm{H}(4) ; 7.28\left(\mathrm{~d}, 1 \mathrm{H},{ }^{3} \mathrm{~J} \quad 3.9\right), 7.37-7.39(\mathrm{~m}, 2 \mathrm{H}) \mathrm{H}$ $\begin{array}{ll}\left(3,3^{\prime}, 4^{\prime}\right) ; 7.44 \text { (d, } 1 \mathrm{H},{ }^{3} \mathrm{~J} & 5.3) \mathrm{H}(5) ; 7.88-7.92(\mathrm{~m}, 3 \mathrm{H}) \mathrm{H}(\mathrm{a}, \mathrm{b}), \mathrm{H}\end{array}$ $\left(2^{\prime \prime}, 3^{\prime \prime}, 5^{\prime \prime}, 6^{\prime \prime}\right) ; 8.37$ (d, $\left.2 \mathrm{H},{ }^{3} \mathrm{~J} \quad 7.0\right) \mathrm{H}\left(2^{\prime \prime}, 3^{\prime \prime}, 5^{\prime \prime}, 6^{\prime \prime}\right) .{ }^{13} \mathrm{C}$ NMR $\left(\mathrm{CD}_{3} \mathrm{CN} ; \delta\right.$; ppm): $48.07\left(\mathrm{CH}_{3}\right) ; 122.17 ; 124.27 ; 126.03 ; 126.38 ; 127.61 ; 129.28$; $134.48 ; 134.71 ; 145.46(\mathrm{CH}) ; 129.55 ; 137.12 ; 140.09 ; 142.07$ (C). Calculated for $\mathrm{C}_{16} \mathrm{H}_{14} \mathrm{ClNO}_{4} \mathrm{~S}_{2}(\%)$ : $\mathrm{C}, 50.06 ; \mathrm{H}, 3.68 ; \mathrm{N}, 3.65$; found (\%): C, $49.90 \mathrm{H}, 3.86$; N, 3.38. ESI-MS in $\mathrm{MeCN}, \mathrm{m} / z$ : calcd. 284.42; found $283.922[\mathrm{M}]$.

\subsubsection{Synthesis of 5,5'-bis((E)-2-(benzo[d] thiazol-2-yl)vinyl)-2,2'- bithiophene (2a)}

[2,2'-Bithiophene]-5,5'-dicarbaldehyde $(0.45 \mathrm{mmol}, 100 \mathrm{mg})$ and 2methylbenzothiazol $(0.9 \mathrm{mmol}, 134 \mathrm{mg}$ ) were dissolved in DMSO, stirred for $10 \mathrm{~min}$ and an aqueous $50 \%$ solution of $\mathrm{KOH}(4 \mathrm{ml})$ was added. Two-layered mixture stayed with no stirring for 2 days. After complete reaction, the precipitate formed was filtered on a glass porous filter, washed with water and methanol. After washing the sediment was transferred into the flask, $1 \mathrm{ml}$ of benzene, carbon tetrachloride, ethyl acetate and methanol each was added to it. The mixture was subjected to ultrasonic treatment for $10 \mathrm{~min}$ at $40 \mathrm{C}$ in darkness, filtered and dried on a rotary evaporator. The pure product was obtained as a red-brown precipitate $\left(0.19 \mathrm{mmol}, 92 \mathrm{mg}\right.$ ). Yield $42 \%$. ${ }^{1} \mathrm{H}$ NMR (DMSO; $\delta$; ppm, J/Hz): 7.28 (d, 2H, $\left.{ }^{3} \mathrm{~J} \quad 15.7\right) \mathrm{H}(\mathrm{a}, \mathrm{b}) ; 7.44\left(\mathrm{t}, 2 \mathrm{H},{ }^{3} \mathrm{~J} \quad 7.8,{ }^{3} \mathrm{~J} \quad 7.5\right) \mathrm{H}$ $(5,6) ; 7.46\left(\mathrm{~d}, 2 \mathrm{H},{ }^{3} \mathrm{~J} \quad 3.7\right) \mathrm{H}\left(1^{\prime}, 2^{\prime}\right) ; 7.51-7.54(\mathrm{~m}, 4 \mathrm{H}) \mathrm{H}\left(1^{\prime}, 2^{\prime}, 5,6\right)$; 
$7.84\left(\mathrm{~d}, 2 \mathrm{H},{ }^{3} \mathrm{~J} \quad\right.$ 15.9) H(a,b); 7.96 (d, $\left.2 \mathrm{H},{ }^{3} \mathrm{~J} \quad 8.3\right), 8.07$ (d, $2 \mathrm{H},{ }^{3} \mathrm{~J}$ 7.8) $\mathrm{H}(4,7)$. Due to the low solubility of the product, it was not possible to characterize it by means of ${ }^{13} \mathrm{C}$ NMR spectroscopy. Calculated for $\mathrm{C}_{26} \mathrm{H}_{16} \mathrm{~N}_{2} \mathrm{~S}_{4}$ (\%): C, 64.43; H, 3.33; N, 5.78; found (\%): C, $64.20 \mathrm{H}, 3.51$; $\mathrm{N}$, 5.54. MS in MeCN, $m / z$ : calcd. 484.6; found 483608 [M-H ]'.

\subsubsection{Synthesis of 2,2'-((1E, $\left.1^{\prime} E\right)-\left[2,2^{\prime}\right.$-bithiophene]-5,5'-diylbis(ethene-}

2,1-diyl))bis(3-methylbenzo[d]thiazol-3-ium) (2b)

Mixture of [2,2'-bithiophene]-5,5'-dicarbaldehyde $(0.315 \mathrm{mmol}, 70$ $\mathrm{mg}$, 2,3-dimethylbenzo[d] thiazol-3-ium perchlorate $(0.63 \mathrm{mmol}$, $166.2 \mathrm{mg}$ ) and $700 \mu \mathrm{l}$ of pyridine in $5 \mathrm{ml}$ of ethanol was refluxed for $12 \mathrm{~h}$ in darkness. After the removing of solvent on a rotary evaporator, the sequence of boiling in $5 \mathrm{ml}$ of ethanol for $5 \mathrm{~min}$ and filtering was repeated twice. The pure product was obtained as a black-violet precipitate (0.2 mmol, $143 \mathrm{mg}$ ), yield $64 \% .{ }^{1} \mathrm{H}$ NMR (DMSO; $\delta$; ppm, J/Hz): 4.33 (s, 6H) $\mathrm{CH}_{3} ; 7.75-7.82(\mathrm{~m}, 6 \mathrm{H}) \mathrm{H}(4,5,6,7, \mathrm{a}, \mathrm{b}) ; 7.89$ (dd, $2 \mathrm{H},{ }^{3} \mathrm{~J}$ $\left.7.8,{ }^{3} \mathrm{~J} \quad 7.4\right) \mathrm{H}(5,6) ; 8.02\left(\mathrm{~d}, 2 \mathrm{H},{ }^{3} \mathrm{~J} \quad 3.9\right) \mathrm{H}\left(1^{\prime}, 2^{\prime}\right) ; 8.24\left(\mathrm{~d}, 2 \mathrm{H},{ }^{3} \mathrm{~J}\right.$ 8.0) $\mathrm{H}(4,7) ; 8.42-8.49$ (m, 4H) H(1', $\left.2^{\prime}, \mathrm{a}, \mathrm{b}\right) .{ }^{13} \mathrm{C}$ NMR (DMSO $\delta$; ppm): $36.29\left(\mathrm{CH}_{3}\right)$; 116.79; 124.26; 127.87; 128.42; 136.56; 139.80; 142.05; $170.85(\mathrm{CH}) ; 112.78 ; 128.05 ; 129.46 ; 139.91 ; 142.17$ (C). Calculated for $\mathrm{C}_{28} \mathrm{H}_{22} \mathrm{Cl}_{2} \mathrm{~N}_{2} \mathrm{O}_{8} \mathrm{~S}_{4}$ (\%): C, 47.12; H, 3.11; N, 3.93; found (\%): C, $46.96 \mathrm{H}$, 3.24; N, 3.72. ESI-MS in MeCN, $m / z$ : calcd. 514.7; found $257.295[\mathrm{M}]^{2}$.

\subsubsection{Synthesis of 2,5-bis(1H-imidazo[4,5-f][1,10]phenanthrolin-2-yl)} thiophene (2d)

1,10-phenanthroline-5,6-dione ( $3 \mathrm{mmol}, 0.6 \mathrm{~g}$ ) was added to the hot solution of thiophene-2,5-dicarbaldehyde $(1.5 \mathrm{mmol}, 210 \mathrm{mg})$ and ammonia acetate $(30 \mathrm{mmol}, 2.31 \mathrm{~g}$ ) in $20 \mathrm{ml}$ of glacial acetic acid. The mixture was refluxed for $6 \mathrm{~h}$ and cooled to the room temperature. Water solution of ammonia (15\%) was added to $\mathrm{pH} \sim 8$. The precipitate formed was filtered on a glass porous filter, washed with water and methanol. The remaining sediment was refluxed in $40 \mathrm{ml}$ of methanol for $30 \mathrm{~min}$. By filtering hot mixture on a glass porous filter the pure product was obtained as a grey-brown powder $(1.05 \mathrm{mmol}, 548 \mathrm{mg}$, yield $70 \%){ }^{1} \mathrm{H}$ NMR (DMSO-d $d_{6} ; \delta$; ppm, J/Hz): 7.85-7.88 (dd, $\left.4 \mathrm{H},{ }^{3} \mathrm{~J} \quad 4.2,{ }^{3} \mathrm{~J} \quad 8.1\right) \mathrm{H}$ $\left(5^{\prime}, 5^{\prime \prime}, 10^{\prime}, 10^{\prime \prime}\right) ; 8.01$ (s, 2H) H(3,4); 8.88 (d, 4H, ${ }^{3} \mathrm{~J}$ 8.0) $\mathrm{H}$ $\left(4^{\prime}, 4^{\prime \prime}, 11^{\prime}, 11^{\prime \prime}\right) ; 9.05$ (d, $\left.4 \mathrm{H},{ }^{3} \mathrm{~J} \quad 4.0\right) \mathrm{H}\left(6^{\prime}, 6^{\prime \prime}, 9^{\prime}, 9^{\prime \prime}\right)$. Due to the low solubility of the product, it was not possible to characterize it by means of ${ }^{13} \mathrm{C}$ NMR spectroscopy. Calculated for $\mathrm{C}_{30} \mathrm{H}_{16} \mathrm{~N}_{8} \mathrm{~S}(\%)$ : C, 69.22; H, 3.10; N, 21.53; found (\%): C, 69.14 H, 3.21; N, 21.31. MALDI-MS $m / z$ : $522[\mathrm{M} H], 544[\mathrm{M} \mathrm{Na}]$.

\subsection{Absorption and emission spectra}

UV-Vis spectra were measured using a two channel spectrophotometer Varian-Cary 300 and an Avantes AvaSpec-2048 spectrophotometer. Fluorescence spectra were measured at $20 \quad 1 \mathrm{C}$ with a FluroLog-3-221(Horiba Scientific) and Agilent Cary Eclipse spectrofluorometers.

\subsection{Determination of quantum yield of the $E \rightleftarrows Z$ photoisomerization}

To determine the quantum yields of the forward and backward reactions of $E \rightleftarrows Z$ photoisomerization of 1a and 1d, we preliminarily calculated the absorption spectra of the corresponding $Z$-isomer and the ratios of quantum yields for the forward and backward reactions of $E \rightleftarrows$ $Z$-photoisomerization using the Fisher method [48] from the absorption spectra of the $E$-isomer and the spectra of two photostationary states obtained by photoirradiation at two different wavelengths.

\subsection{Fluorescence quantum yield}

All measured fluorescence spectra were corrected for nonuniformity of detector spectral sensitivity. Anthracene ( $\left.\phi_{\mathrm{fl}} \quad 0.27\right)$, tris(bipyridine) ruthenium(II) chloride ( $\left.\phi_{\mathrm{fl}} \quad 0.028\right)$, coumarine 6 ( $\left.\phi_{\mathrm{fl}} \quad 0.78\right)$ and rhodamine $6 \mathrm{G}\left(\phi_{\mathrm{fl}} \quad 0.95\right)$ in ethanol were used as references for the fluorescence quantum yield measurements.

\subsection{Fluorescence decay measurements}

Fluorescence decay measurements of $\mathbf{1} \mathbf{a}-\mathbf{d}$ in MeCN were carried out using the following system. A Ti:sapphire laser system emitting pulses of $0.6 \mathrm{~mJ}$ and $30 \mathrm{fs}$ at $800 \mathrm{~nm}$ and $1 \mathrm{kHz}$ pulse repetition rate (Femtopower Compact Pro) with home-built optical parametric generator and frequency mixers was used to excite the samples at the maximum of the steady-state absorption band. All excited-state lifetimes were obtained by using depolarized excitation light. The highest pulse energies used to excite fluorescence did not exceed $100 \mathrm{~nJ}$ and the average power of excitation beam was $0.1 \mathrm{~mW}$ at a pulse repetition rate of $1 \mathrm{kHz}$ focused into a spot with a diameter of $0.1 \mathrm{~mm}$ in the $10 \mathrm{~mm}$-long fused-silica cell. The fluorescence emitted in the forward direction was collected by reflective optics and focused with a spherical mirror onto the input slit of a spectrograph (Chromex 250) coupled to a streak camera (Hamamatsu 5680 equipped with a fast single sweep unit M5676, temporal resolution $2 \mathrm{ps}$ ). Convolution of a rectangular streak camera slit in the sweep range of 250 ps with electronic jitter of the streak camera trigger pulse provided a Gaussian (over four decades) temporal apparatus function with a full width at half-maximum of 20 ps. The fluorescence kinetics

were later fitted by means of the Levenberg-Marquardt least-squares curve-fitting method using a solution of the differential equation describing the evolution in time of a single excited state and neglecting depopulation of the ground state according to Eq. (1),

$\frac{d I}{d t} \quad$ Gauss $t_{0}, \Delta t, A \quad \frac{I t}{\tau}$

where $I(\mathrm{t})$ is the fluorescence intensity, Gauss is the Gaussian profile of the excitation pulse, in which $t_{0}$ is the excitation pulse arrival delay, $\Delta t-$ the excitation pulse width, and $A$ - the amplitude. The parameter $\tau$ is the lifetime of the excited state. The initial condition for the equation is $I$ $(-\infty)$ 0. Typically, the fit shows a $\chi^{2}$ value (Pirson's criteria) better than $10^{4}$ and a correlation coefficient $R>0.999$. The uncertainty of the lifetime was better than $1 \%$. Routinely, the fluorescence accumulation time in our measurements did not exceed $90 \mathrm{~s}$.

Fluorescence decay measurements of $\mathbf{2 a - d}$ in $\mathrm{MeCN}$ were carried out using a spectrofluorometer FluoroLog-3-221 (Horiba Scientific) equipped with Time-Correlated Single Photon Counting (TCSPC) module and solid-state pulsed NanoLED emitting at $455 \mathrm{~nm}$ and $1 \mathrm{MHz}$ pulse repetition rate. To determine fluorescence lifetimes the fluorescence kinetics were analyzed by fitting the decay curves with the use of the DAS6 program. The relative accuracy of the lifetime measurements done under the same conditions was $0.01 \mathrm{~ns}$.

\subsection{Voltammetry studies}

Electrochemical measurements were carried out at $22 \mathrm{C}$ with an IPCProM potentiostat. Cyclic voltammetry experiments were performed in a $1.0 \mathrm{~mL}$ cell equipped with a glassy carbon (GC) electrode (disk d 2 $\mathrm{mm}$ ), $\mathrm{Ag} / \mathrm{AgCl} / \mathrm{KCl}$ (aq. saturated; reference electrode), and platinum electrode (counter electrode). Compounds were dissolved in degassed dry $\mathrm{CH}_{3} \mathrm{CN}$ or DMF containing TBAP as the supporting electrolyte $(0.1$ $\mathrm{M})$. Dry argon gas was bubbled through the solutions for $30 \mathrm{~min}$ before cyclic voltammetry experiments. The scan rate was $200 \mathrm{mV} \mathrm{s}^{1}$.

\subsection{Charge carrier mobility and conductivity measurements}

In thin layers of the composites, charge carrier mobility $(\mu)$ was measured by using the technique of charge extraction by linearly 
increasing voltage (CELIV) with metal-insulator-semiconductor (MIS) diode structures. A thin layer $\left(d_{\mathrm{s}} 130 \mathrm{~nm}\right)$ of the PF-EP/TD composite (5 wt \%) was deposited onto the $\mathrm{SiO}_{2} / \mathrm{ITO} /$ glass substrate by spin coating of the $5 \mathrm{mg} / \mathrm{ml}$ solution in the ethanol/acetonitrile (95/5 vol) mixture at rate of $1000 \mathrm{rpm}$ and dried at $60 \mathrm{C}$ for $3 \mathrm{~h}$. Then a $80 \mathrm{~nm}$ thick Al top electrode was deposited onto the composite layer by thermal evaporation under $10{ }^{6}$ mbar vacuum at rate of $1 \AA$ s. A charge carrier blocking $\mathrm{SiO}_{2}$ layer of $70 \mathrm{~nm}$ thick was preliminary deposited onto ITOcoated glass by magnetron scattering at $10^{3}$ mbar.

The CELIV set-up included a digital USB-oscilloscope (DL-Analog Discovery, Digilent Co.), which played roles of master pulse generator and transient current pulse monitor. $R C$ constants were at least a factor of 20 smaller than the time scales of interest. The bias was swept in the range between 10 and $100 \mathrm{kHz}$.

A small charge extraction regime of the MIS-CELIV experiment was used. The condition $\Delta \mathrm{j} \quad \mathrm{j}(0)$ where $\Delta \mathrm{j}$ is a maximum current of unipolar charge carriers and $\mathrm{j}(0)$ is a capacitance current [49]. The corresponding small-charge transit time $t_{\max }$ for the sheet of carriers to reach the extracting contact defines the mobility as following [49]:

$\mu \frac{2 d_{s}^{2}}{A t_{\max }^{2} 1 \quad f}$

where the ratio between the geometric capacitances of the organic semiconductor and the $\mathrm{SiO}_{2}$ insulator layers $f\left(\varepsilon_{\mathrm{s}} d_{\mathrm{i}}\right) /\left(\varepsilon_{\mathrm{i}} d_{\mathrm{s}}\right)$ is ranged between $\sim 0.34$ and $\sim 0.45$ for dielectric constants $\varepsilon_{\mathrm{i}}$ is $\varepsilon_{\mathrm{i}} \quad 3.9$ and $\varepsilon_{\mathrm{s}}$ $\sim 2.5$ for $\mathrm{SiO}_{2}$ and PF-EP/TD (5 wt\%) composite, respectively.

The electrical conductivity of thin films was measured using the fourprobe technique in the 4-stripe layout as described in Ref. [50]. The Al electrodes were made as parallel stripes of $10 \mathrm{~mm}$ in width with equal distance of $0.7 \mathrm{~mm}$ between neighbors. The outer and inner pairs of the electrodes served as current and voltage contacts, respectively. Electrical measurements were carried out in a glovebox with Ar atmosphere at room temperature using Keithley 236 and 2400 source-meter units and a standard probe station (MPI ITS50COAX) setup. The thickness of the films was ranged between 100 and $120 \mathrm{~nm}$. The relative error of the conductivity measurements was $15 \%$.

\subsection{OLED devices fabrication and characterization}

PEDOT:PSS solution (Heraeus, Clevios P VP. Al 4083) was spincoated onto the ITO-coated glass substrates at 2000 r.p.m. for $60 \mathrm{~s}$ and baked at $110 \mathrm{C}$ for $30 \mathrm{~min}$. The PEDOT:PSS-coated substrates were transferred into an argon-filled glove box $\left(\mathrm{O}_{2}<1\right.$ p.p.m., $\mathrm{H}_{2} \mathrm{O}<1$ p.p. $\mathrm{m}$.). Poly-TPD in chlorobenzene $(8 \mathrm{mg} / \mathrm{ml})$ and PVK in o-xylene $(1.5$ $\mathrm{mg} / \mathrm{ml}$ ) were deposited layer by layer by spin coating at 2000 r.p.m. for $45 \mathrm{~s}$. Deposited in succession poly-TPD and PVK layers were baked at $110 \mathrm{C}$ for $20 \mathrm{~min}$ and at $140 \mathrm{C}$ for $30 \mathrm{~min}$, respectively. A PF layer was spin-cast over PVK layer from a toluene solution at 1500 r.p.m for $1 \mathrm{~min}$ and dried at $80 \mathrm{C}$ for $3 \mathrm{~h}$. Then a $20 \mathrm{~nm}$ thick layer of the PF-EP/TD composite ( $5 \mathrm{wt} \%$ ) was deposited by spin coating of $5 \mathrm{mg} / \mathrm{ml}$ solution in the ethanol/acetonitrile $(95 / 5 \%$ vol.) mixture at rate of 1000 r.p.m and dried at $60 \mathrm{C}$ for $3 \mathrm{~h}$. Finally $\mathrm{LiF}(1 \mathrm{~nm}) / \mathrm{Al}(80 \mathrm{~nm})$ cathode was deposited onto the composite layer through a shadow mask by thermal evaporation under $210{ }^{6}$ mbar vacuum. The device area was $9 \mathrm{~mm}^{2}$.

The EL spectra of OLEDs were recorded on an Avantes 2048 fiberoptic spectrofluorimeter (Netherlands). Voltage-current and voltage-brightness characteristics were measured with Keithley 2601 SourceMeter (USA), Keithley 485 pico-ammeter and TKA-04/3 luxmeterbrightness meter (Russia). The thicknesses of the films were determined using MII-4 interferometer (LOMO, St.-Petersburg, Russia). The preparation of OLED samples and measurements of their spectral and optoelectronic characteristics were performed at room temperature under argon atmosphere.

\section{Results and discussion}

Mono- (1 a-d) and bisubstituted thiophene containing TDs 2a-d were synthesized as shown on Scheme 1. Synthesis includes the condensation reaction of 2,2'-bithiophene-5-carbaldehyde or 2,2'-bithiophene-5,5'dicarbaldehyde with 2-methylbenzo[d]thiazole, 7-methylbenzo[1,2d:3,4-d']bis(thiazole)-2-amine, 2,3-dimethylbenzo[d] thiazol-3-ium perchlorate, 1,4-dimethylpyridin-1-ium perchlorate and 1,10-phenanthroline-5,6-dione (see Experimental part). TD 2d is the only containing one thiophene moiety. TD 2c is known in literature [47]. The other TDs were synthesized for the first time. Their structures were proved by ${ }^{1} \mathrm{H},{ }^{13} \mathrm{C}$ NMR, ESI-MS, elemental analysis.

\subsection{Optical and electrochemical properties}

The absorption and emission maxima of TDs 1a-d and 2a-d are listed in Table 1 and Figs. S1-S16 in ESI. Comparing the absorption data for TDs $1 \mathbf{a}$ and 1c, it can be seen that the replacement of the benzothiazole ring by a benzobis(thiazole) leads to a bathochromic shift up to $33 \mathrm{~nm}$, related to an increased size of heterocyclic residue in compound $\mathbf{1 c}$. Also, TD 2a possessing two vinylbenzothiazole residues demonstrates the long wavelength absorption band which is $65 \mathrm{~nm}$ bathochromically shifted compared to 1a. The long wavelength absorption band for positive charged TDs $\mathbf{1} \mathbf{b}, \mathbf{d}$ and $\mathbf{2} \mathbf{b}$ was shifted bathochromically relative to neutral TDs 1a, 2a. In case of TDs $\mathbf{2 c}$ and $\mathbf{2 d}$ the bathochromic shift of long wavelength absorption band is observed when going from $\mathbf{2 d}$ to $\mathbf{2 c}$ as the number of thiophene units increased, as expected from the increase of conjugation length. The same trend was observed in the emission spectra of these compounds as the position of the wavelength of maximum emission was red-shifted for each added thiophene,

Table 1

Optical and electrochemical characteristics of TDs 1a-d and 2a-d. $\boldsymbol{E}_{\mathrm{pc}}$ and $\boldsymbol{E}_{\mathrm{pa}}$ stand for redox potentials of compounds, $\lambda^{\text {abs }}{ }_{\max }$ and $\lambda_{\text {max }}^{\mathrm{fl}}$ - absorption and fluorescence peaks maxima respectively, $\Phi_{\mathrm{fl}}$ and $\Phi_{E-Z} / \Phi_{Z-E}$ - quantum yields of fluorescence and $E-Z / Z-E$ isomerization respectively, $\mathrm{T}$ - fluorescence lifetimes.

\begin{tabular}{|c|c|c|c|c|c|c|c|}
\hline $\mathrm{TD}$ & $E_{\text {red }}, \mathrm{V}^{\mathrm{a}}$ & $\begin{array}{l}E_{o x}, \\
\mathrm{~V}\end{array}$ & $\begin{array}{l}\lambda_{\text {max }}^{\text {abs }} \\
\mathrm{nm}^{\mathrm{b}}\end{array}$ & $\begin{array}{l}\lambda^{\mathrm{fl}} \max \\
\mathrm{nm}\end{array}$ & $\begin{array}{l}\Phi_{\mathrm{fl}}, \\
\%\end{array}$ & $\begin{array}{l}\Phi_{E-Z /} / \\
\Phi_{Z-E}, \\
\%\end{array}$ & $\mathrm{~T}, \mathrm{ps}$ \\
\hline $1 \mathrm{a}$ & $\begin{array}{l}1.50 \\
1.80\end{array}$ & $\begin{array}{l}1.14 \\
1.49 \\
1.69\end{array}$ & 386 & 498 & 0,2 & $55 / 13$ & 30 \\
\hline $1 b$ & $\begin{array}{l}0.58 \\
1.87\end{array}$ & $\begin{array}{l}1.41 \\
1.79\end{array}$ & 472 & 597 & 0,5 & c & 30 \\
\hline $1 c$ & $\begin{array}{l}1.10 \\
1.49\end{array}$ & 1.88 & 419 & 485 & 11.5 & - & $\begin{array}{l}7, \\
770 \\
(12 \%)\end{array}$ \\
\hline 1d & $\begin{array}{l}0.87 \\
1.53\end{array}$ & $\begin{array}{l}1.37 \\
1.75\end{array}$ & 431 & 579 & 2,0 & $55 / 56$ & $\begin{array}{l}83 \\
163 \\
(31 \%)\end{array}$ \\
\hline $2 a$ & $\begin{array}{c}1.30 /- \\
1.21 \\
1.50 \\
1.83\end{array}$ & $\begin{array}{l}1.20 \\
1.41\end{array}$ & 451 & 550 & 10,3 & d & 570 \\
\hline $2 b$ & $\begin{array}{c}0.41 /- \\
0.35 \\
1.72\end{array}$ & $\begin{array}{l}1.69 \\
1.77\end{array}$ & 525 & 619 & 8,4 & c & 320 \\
\hline $2 c$ & $\begin{array}{l}1.12 \\
1.39\end{array}$ & $\begin{array}{l}0.91 \\
1.17 \\
1.31\end{array}$ & 400,423 & 640 & 23,3 & - & $\begin{array}{l}1260 \\
(8.3 \%) \\
2700 \\
(91.7 \%)\end{array}$ \\
\hline $2 d$ & $\begin{array}{l}0.88 \\
1.41\end{array}$ & $\begin{array}{l}0.51 \\
1.09 \\
1.26\end{array}$ & 388 & 535 & 29,7 & - & 2100 \\
\hline
\end{tabular}

${ }^{\text {a }}$ Electrochemical characteristics were measured in MeCN (1a-c, 2b) or DMF (2a,c,d).

b Optical spectra were recorded in $\mathrm{MeCN}$.

c Fast back cis-trans-reaction.

d Photoisomerization process included isomerization around two double $\mathrm{C}=\mathrm{C}$ bonds. 
increase of the heterocyclic residue size and replacement of neutral residue with positively charged (Table 1 ). The synthesized compounds showed large Stokes' shift (the lowest being for 1c and the highest for 2d). A large Stokes shift is an important characteristic for a fluorescent probe that allows an improved separation of the light inherent to the matrix and the light dispersed by the sample [50].

The measured fluorescence quantum yields have values ranging from 0.2 to $29.7 \%$. . Irradiation of TDs 1a,d with light at $405 \mathrm{~nm}$ and $436 \mathrm{~nm}$, respectively, causes $E, Z$-photoisomerization with a fairly high quantum yield (0.55), while reverse $Z$, $E$-photoisomerization is less effective for $\mathbf{1 a}$ and comparable to direct photoisomerization for 1d (Table 1 . Compounds $\mathbf{1 b}$ and

$\mathbf{2 b}$ also demonstrate the $E, Z$-photoisomerization with high rate of the reverse isomerization in the dark

In case of $\mathbf{2 a}$ the photoisomerization occurs with participation of two double bonds $[26,34,42]$,

Some experiments were carried out by ultrafast techniques (Table 1 ) in order to reveal the possible role of upper excited states and/or primary steps involving precursor transients. Only the $S_{1} \rightarrow S_{n}$ transient was observed for 1a-c, with a decay rate corresponding to the fluorescence lifetime. The other TDs possess longer lifetime of fluorescence. In case of $\mathbf{2} \mathbf{c}, \mathbf{d}$ temporal range can indicate a fast ISC and irradiative relaxation of exited state.

The redox properties of $\mathbf{1 a - d , 2 a , b}$ were investigated by cyclic wave voltammetry in $\mathrm{MeCN}$ or DMF containing tetrabutylammonium perchlorate as supporting electrolyte. The resulting electrochemical data are summarized in Table 1 . The

HOMO and LUMO energy levels are compiled in Table 2. From Table 2, the band gaps of 1a-d and 2ad lay from $1.39 \mathrm{eV}$ (2d) up to $2.98 \mathrm{eV}$ (1c), which are in good agreement with the optical band gaps. In series of 1a-d compounds, 1b with stronger electron withdraw benzothiazolium heterocyclic group results in a lower LUMO level of $4.15 \mathrm{eV}$ and a narrower band gap (1.99 eV). In case of compounds 2a-d, lower LUMO level of $4.32 \mathrm{eV}$ belongs to $\mathbf{2 b}$, whereas, a narrower band gap (1.39 eV) was observed for $\mathbf{2 d}$.

\subsection{The charge transport study}

PF-EP was used as a wide band-gap polymer matrix with HOMO and LUMO levels of $5.7 \mathrm{eV}$ and $2.2 \mathrm{eV}$ [51], respectively. That is why the studied materials exhibited low electrical conductivity. The 4-probe technique measurements showed that it equals to $6 \quad 10^{5} \mathrm{~S} / \mathrm{cm}$ for the PF-EP films and ranges between $7 \quad 10^{5}$ and $1 \quad 10^{4} \mathrm{~S} / \mathrm{cm}$ for $\mathrm{PF}-\mathrm{EP} / \mathrm{TD}$ thin films . To determine charge carriers mobility we used the MIS-CELIV technique

[52-54]. Due to the presence of electron donor and acceptor moieties in the molecules (Table 2), they exhibit ambipolar charge transporting properties. HOMO and LUMO levels afford the hopping transport of holes and electrons, respectively.

The electron mobility values in all the PF- EP/TD composites, except for PF- EP/1d, are larger than that in the PF-EP. We believe that the

Table 2

LUMO-HOMO levels (eV) for TDs and charge carrier mobility $\left(\mathrm{cm}^{2} \mathrm{~V}^{1} \mathrm{~s}^{1}\right)$ in PFEP doped with TDs (5 wt \%).

\begin{tabular}{lcclcl}
\hline Material & LUMO & \multicolumn{2}{l}{ Electron mobility } & HOMO & Hole mobility \\
\hline PF-EP & 2.2 & 3.0 & $2.50 \cdot 10^{5}$ & 5.7 & $1.94 \cdot 10^{4}$ \\
PF- EP 1a & 3.23 & & $1.50 \cdot 10^{4}$ & 5.87 & $3.27 \cdot 10^{5}$ \\
PF- EP 1b & 4.15 & $9.43 \cdot 10^{5}$ & 6.14 & $1.42 \cdot 10^{4}$ \\
PF- EP 1c & 3.63 & $2.34 \cdot 10^{4}$ & 6.61 & $7.15 \cdot 10^{5}$ \\
PF- EP 1d & 3.86 & $1.05 \cdot 10^{5}$ & 6.10 & $6.45 \cdot 10^{5}$ \\
PF- EP 2a & 3.43 & - & & 5.93 & $9.50 \cdot 10^{6}$ \\
PF- EP 2b & 4.32 & - & 6.42 & $4.30 \cdot 10^{6}$ \\
PF- EP 2c & 3.61 & $6.00 \cdot 10^{5}$ & 5.64 & $1.30 \cdot 10^{5}$ \\
PF- EP 2d & 3.85 & $1.09 \cdot 10^{4}$ & 5.24 & $3.28 \cdot 10^{5}$ \\
\hline
\end{tabular}

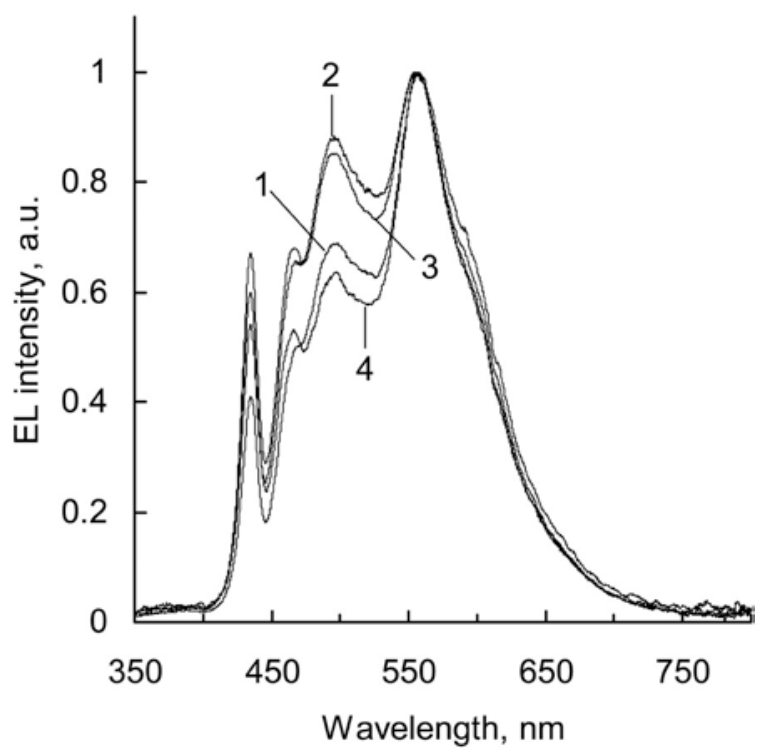

Fig. 1. EL spectra of the studied PLED that has no TD component in the PF-EP electron. transport layer (1) and three other samples with 1a (2), 1b (3) and 1d (4).

main reasons for the enhancement of the charge mobility are following: (a) TDs themselves serve as charge transport sites, (b) charge-transfer states formed by TDs and PF-EP are involved in the transport. According to the concentration of TDs in the polymer, the mean distance between neighboring molecules does not exceed $2 \mathrm{~nm}$ provided they are distributed uniformly. That is why they are really able to participate in the electron transport. Moreover, the LUMO levels of the TDs are located at least $1 \mathrm{eV}$ lower than that of PF-EP, so the polymer matrix does not hamper the electron transport. The hole mobility in the PF-EP/TD composites appeared to be lower than that for the PF-EP. Since the HOMO level of the PF-EP is located about $1 \mathrm{eV}$ higher than that of PF-EP/ TD, the TDs serve as hole traps. Thus, basing on the conductivity and charge carrier mobility data, we reveal that a few tens nanometers thick layer of such materials can serve as an ETL.

Table 3

EL characteristics of the studied PLEDs with different electron injection/transport layers.

\begin{tabular}{|c|c|c|c|c|c|c|}
\hline \multirow{2}{*}{$\begin{array}{l}\text { Electron } \\
\text { transport } \\
\text { layer }\end{array}$} & \multirow{2}{*}{$\begin{array}{l}\mathrm{U}_{\mathrm{on}}, \\
\mathrm{V}\end{array}$} & \multirow{2}{*}{$\begin{array}{l}\text { Brightness, } \\
\mathrm{cd} / \mathrm{m}^{2} \\
\mathrm{U} \quad 15 \mathrm{~V}\end{array}$} & \multicolumn{2}{|c|}{ Max. efficiency } & \multirow{2}{*}{$\begin{array}{l}\text { CIE, } \\
\mathrm{x}, \mathrm{y}\end{array}$} & \multirow{2}{*}{$\begin{array}{l}\lambda_{\max } \\
\mathrm{EL}, \\
\mathrm{nm}\end{array}$} \\
\hline & & & $\begin{array}{l}\text { Current } \\
\mathrm{cd} / \mathrm{A}\end{array}$ & $\begin{array}{l}\text { Luminousity } \\
\mathrm{lm} / \mathrm{W}\end{array}$ & & \\
\hline PF-EP & 10 & 1080 & 1.01 & 0.26 & $\begin{array}{l}0.340 \\
0.433\end{array}$ & $\begin{array}{l}435, \\
465, \\
494, \\
556, \\
598\end{array}$ \\
\hline $\begin{array}{r}\text { PF-EP } \\
\mathbf{1 a}\end{array}$ & 13 & 970 & 0.17 & 0.03 & $\begin{array}{l}0.313 \\
0.416\end{array}$ & $\begin{array}{l}435, \\
465, \\
494, \\
556, \\
598\end{array}$ \\
\hline $\begin{array}{r}\text { PF-EP } \\
\mathbf{1 b}\end{array}$ & 9 & 1770 & 0.64 & 0.17 & $\begin{array}{l}0.311 \\
0.403\end{array}$ & $\begin{array}{l}435, \\
465, \\
494, \\
556, \\
598\end{array}$ \\
\hline $\begin{array}{r}\text { PF-EP } \\
\text { 1d }\end{array}$ & 8.5 & 1910 & 0.54 & 0.17 & $\begin{array}{l}0.341 \\
0.411\end{array}$ & $\begin{array}{l}435, \\
465, \\
494, \\
556, \\
598\end{array}$ \\
\hline
\end{tabular}



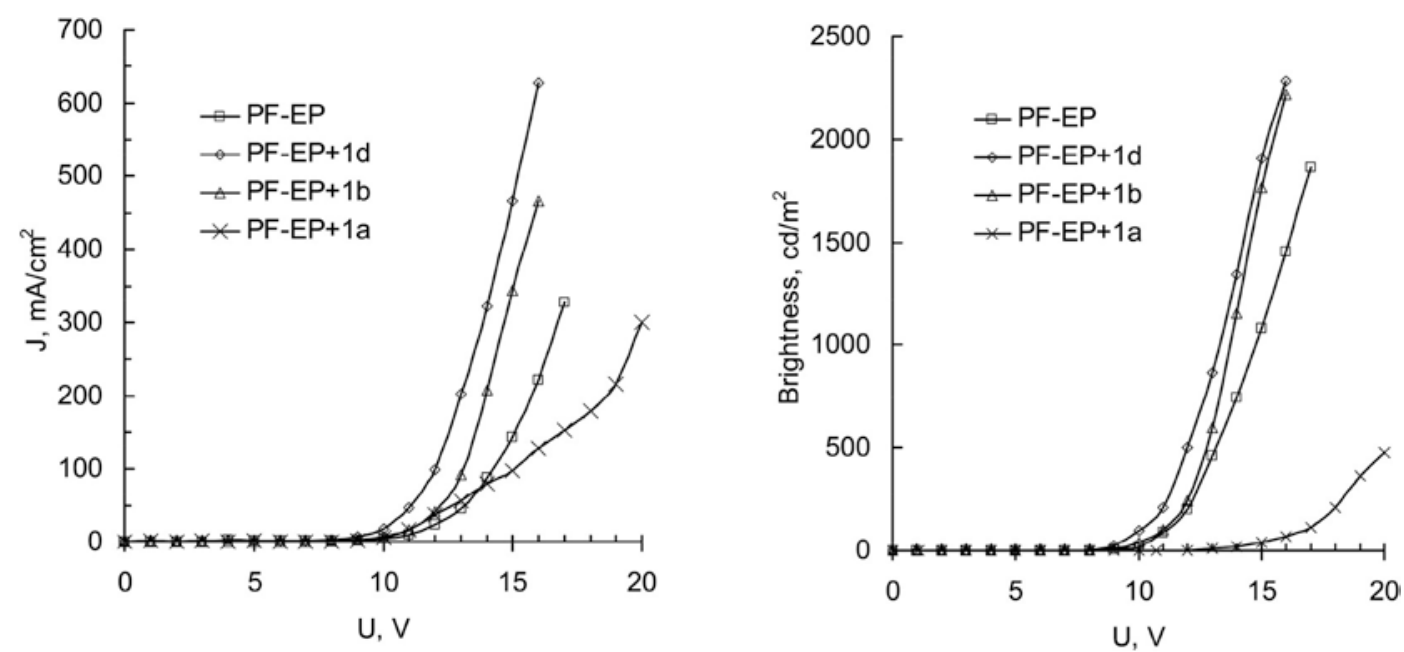

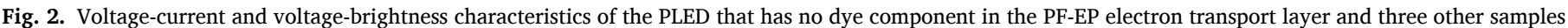
with 1a, 1b and 1d.

\subsection{Styrylthiophene in composition of polymer light-emitting diodes (PLEDs)}

Conjugated polyelectrolytes and organic salts attract particular attention due to their use as efficient electron injection/transport layers $[55,56]$. We investigated the effect of styrylthiophen-containing derivatives in the electron injection/transport layers on the EL characteristics of PLEDs. A series of EL structures containing a polyfluorene derivative (PF) as a light-emitting layer (Scheme 2) was manufactured. Concentration of the TDs in the composites was $5 \%$ by weight. The PLEDs exhibited electroluminescence in the entire visible spectral region (Fig. 1).

Composites based on PF-EP and 1a, 1 b and 1d were used as electron transport layers (ETLs). The EL spectra of the PLEDs slightly differ (Fig. 1). Table 3 shows that for a series of samples with $\mathbf{1 b}$ and $\mathbf{1 d}$, luminescence voltage onsets decrease and equal 9 and $8.5 \mathrm{~V}$, respectively, in contrast to the ETL based on the pure PF-EP (10V) and composite containing 1a (13V) (Fig. 2). It is noteworthy, that at the voltage of $15 \mathrm{~V}$, brightness of the samples in the presence of $\mathbf{1 b}$ and $1 \mathbf{d}$ was twice as high as that of a PLED with pure PF-EP. For the most of PFs with different substituents, the HOMO and LUMO levels are in the range 5.5 to $5.7 \mathrm{eV}$, and 2.5 to $3 \mathrm{eV}$, correspondingly [57]. The LUMO levels of the compounds $\mathbf{1 b}$ and $\mathbf{1 d}$ of 4.15 and $3.86 \mathrm{eV}$, respectively, act as levels that promote electron injection into the composite from $\mathrm{Al}$ (work-function $4.3 \mathrm{eV}$ ). The TD 1a with the LUMO level of $3.23 \mathrm{eV}$, on the other hand, does not improve the electron transfer to PF-EP. While the electron and hole mobility imbalance increases in the PF-EP 1a composite (Table 2), both the current density and brightness of the PF-EP 1a based PLED decrease compared with those of the PF-EP based PLED.

\section{Conclusion}

We have synthesized mono- and bisubstituted thiophene derivatives containing a $\pi$-electron donor thiophene moiety (or moieties) connected through a double bond as a linker with a $\pi$-electron heterocyclic acceptor and studied them as dopants in the conducting polymer layers of PF-EP.

The photophysical and electrochemical measurements allowed us to obtain new data on the optical properties of these compounds and determine their frontier-orbital energy levels. It was revealed that the prepared compounds are able to participate in E,Z-photoisomerization. The neutral derivatives $1 \mathbf{a}, \mathbf{1} \mathbf{c}$ and $2 \mathrm{a}$ possess larger fluorescence quantum yields as compare with positively charged molecules $\mathbf{1 b}, \mathbf{1 d}$ and $\mathbf{2 b}$. All they demonstrate a large Stocks shift.

We have found that incorporation of TD molecules into the PF-EP polymer improves electron transport in the composite. In particular, for composites with TDs 1a, 1b, 1c, 1d, the electron mobility increases in the following sequence $\mathbf{1 d}<$ TD free $<\mathbf{1 b}<\mathbf{1 a}<\mathbf{1 c}$ (Table 2). However, in the operating voltage mode on LEDs with ETLs containing these composites, the current and brightness increase in the sequence $\mathbf{1 a}<$ TD free $<\mathbf{1 b}<\mathbf{1 d}$ (Fig. 2). This indicates that it is the effective electron injection due to the lower lying LUMO levels of TDs (namely, 1b and 1d) relative to the LUMO level in the PF-EP and not electron transport in the ETLs plays a key role in the operation of the manufactured LEDs.

The light-emitting diodes made of PF-EP composites containing $\mathbf{1 b}$ and 1d showed almost two times higher brightness at $15 \mathrm{~V}$ when compared with a diode made of pure PF-EP.

Thus, the vinylthiophene derivatives containing heterocyclic acceptor substituents let one to produce the compounds that improve ambipolar charge transport. The further synthesis and analysis of such structures may be considered as a promising approach to the development of new electroactive composites with better optoelectronic characteristics.

\section{Declaration of competing interest}

The authors declare that they have no known competing financial interests or personal relationships that could have appeared to influence the work reported in this paper.

\section{Acknowledgments}

Financial support from the Russian Science Foundation (RSF N-1773-30036) and equipment facilities from Center of collective facilities of A. N. Nesmeyanov Institute of Organoelement compounds of Russian Ministry of Sciences and High Education are gratefully acknowledged.

\section{References}

[1] S.R. Forrest, The path to ubiquitous and low-cost organic electronic appliances on plastic, Nature 428 (2004) 911-918. 
[2] J.H. Burroughes, D.D.C. Bradley, A.R. Brown, R.N. Marks, K. Mackay, R.H. Friend, et al., Light-emitting-diodes based on conjugated polymers, Nature 347 (1990) 539-541.

[3] Y.G. Li, W. Zhou, H.L. Wang, L.M. Xie, Y.Y. Liang, F. Wei, et al., An oxygen reduction electrocatalyst based on carbon nanotube-graphene complexes, Nat. Nanotechnol. 7 (2012) 394-400.

[4] M. Skompska, Hybrid conjugated polymer/semiconductor photovoltaic cells, Synth. Met. 160 (2010) 1-15.

[5] D.W. Hatchett, M. Josowicz, Composites of intrinsically conducting polymers as sensing nanomaterials, Chem. Rev. 108 (2008) 746-769.

[6] Z.U. Khan, J. Edberg, M.M. Hamedi, R. Gabrielsson, H. Granberg, L. Wagberg, Thermoelectric polymers and their elastic aerogels, Adv. Mater. 28 (2016) 4556-4562.

[7] G. Wang, L. Zhang, J. Zhang, A review of electrode materials for electrochemical supercapacitors, Chem. Soc. Rev. 41 (2012) 797-828.

[8] R. Gangopadhyay, A. De, Conducting polymer nanocomposites: a brief overview, Chem. Mater. 12 (2000) 608-622.

[9] C. Janaky, K. Rajeshwar, The role of (photo) electrochemistry in the rational design of hybrid conducting polymer/semiconductor assemblies: from fundamental concepts to practical applications, Prog. Polym. Sci. 43 (2015) 96-135.

[10] X. Ji, Y. Xu, W. Zhang, L. Cui, J. Liu, Review of functionalization, structure and properties of graphene/polymer composite fibers, Composites, Part A 87 (2016) 29-45.

[11] K. Rajeshwar, N.R. De Tacconi, C.R. Chenthamarakshan, Semiconductor-based composite materials: preparation, properties, and performance, Chem. Mater. 13 (2001) 2765-2782.

[12] P. Gomez-Romero, Hybrid organic-inorganic materials -in search of synergic activity, Adv. Mater. 13 (2001) 163-174.

[13] B. Walker, C. Kim, T.Q. Nguyen, Small molecule solution-processed bulk heterojunction solar cells, Chem. Mater. 23 (2011) 470-482.

[14] Y.W. Li, Q. Guo, Z.F. Li, J.N. Pei, W.J. Tian, Solution processable D-A small molecules for bulk-heterojunction solar cells, Energy Environ. Sci. 3 (2010) 1427-1436.

[15] M. Lloyd, J. Anthony, G. Malliaras, Photovoltaics from soluble small molecules, Mater. Today 10 (2007) 34-41.

[16] J. Roncali, Molecular bulk heterojunctions: an emerging approach to organic solar cells, Acc. Chem. Res. 42 (2009) 1719-1730.

[17] S. Loser, C.J. Bruns, H. Miyauchi, R.P. Ortíz, A. Facchetti, S.I. Stupp, A naphthodithiophene-diketopyrrolopyrrole donor molecule for efficient solution processed solar cells, J. Am. Chem. Soc. 133 (2011) 8142-8145.

[18] B. Walker, A.B. Tamayo, X.D. Dang, P. Zalar, J.H. Seo, A. Garcia, Nanoscale phase separation and high photovoltaic efficiency in solution-processed, small-molecule bulk heterojunction solar cells, Adv. Funct. Mater. 19 (2009) 3063-3069.

[19] H.X. Shang, H.J. Fan, Y. Liu, W.P. Hu, Y.F. Li, X.W. Zhan, A solution-processable starshaped molecule for high-performance organic solar cells, Adv. Mater. 23 (2011) 1554-1557.

[20] B. Yin, L.Y. Yang, Y.S. Liu, Y.S. Chen, Q.J. Qi, F.L. Zhang FL, Solution-processed bulk heterojunction organic solar cells based on an oligothiophene derivative, Appl. Phys. Lett. 97 (2010), 023303.

[21] Y.J. Cheng, S.H. Yang, C.S. Hsu, Synthesis of conjugated polymers for organic solar cell applications, Chem. Rev. 109 (2009) 5868-5923.

[22] R.K. Kanaparthi, J. Kandhadi, L. Giribabu, Metal-free organic dyes for dye sensitized solar cells: recent advances, Tetrahedron 68 (2012) 8383-8393.

[23] C. Wang, H. Dong, W. Hu, Y. Liu, D. Zhu, Semiconducting $\pi$-conjugated systems in field-effect transistors: a material odyssey of organic electronics, Chem. Rev. 112 (2012) 2208-2267.

[24] C. Di, F. Zhang, D. Zhu, Multi-functional integration of organic field-effect transistors (OFETs): advances and perspectives, Adv. Mater. 25 (2013) 313-330.

[25] J. Zaumseil, H. Sirringhaus, Electron and ambipolar transport in organic fieldeffect transistors, Chem. Rev. 107 (2007) 1296-1323.

[26] H. Yan, Z.H. Chen, Y. Zheng, C. Newman, J.R. Quinn, F. Dotz, M. Kastler, M. A. Facchetti, A high-mobility electron-transporting polymer for printed transistors, Nature 457 (2009) 679.

[27] H. Klauk, U. Zschieschang, J. Pflaum, M. Halik, Ultralow-power organic complementary circuits, Nature 445 (2007) 745.

[28] F.S. Kim, X.G. Guo, M.D. Watson, S.A. Jenekhe, High-mobility ambipolar transistors and High gain inverters from a donor-acceptor copolymer semiconductor, Adv. Mater. 22 (2010) 478-482.

[29] M. Muccini, A bright future for organic field-effect transistors, Nat. Mater. 5 (2006) 605.

[30] R. Capelli, S. Toffanin, G. Generali, H. Usta, A. Facchetti, M. Muccini, Organic light-emitting transistors with an efficiency that outperforms the equivalent light emitting diodes, Nat. Mater. 9 (2010) 496.

[31] M. Muccini, W. Koopman, S. Toffanin, The photonic perspective of organic lightemitting transistors, Laser Photonics Rev. 6 (2012) 258-275.

[32] (a) J. Roncali, Synthetic principles for bandgap control in linear $\pi$-conjugated systems, J. Chem. Rev. 97 (1997) 173-206; (b) S. Zrig, P. Remy, B. Andrioletti, E. Rose, I. Asselberghs, K.J. Clays, Engineering tuneable light-harvesting systems with oligothiophene donors and mono- or bisbodipy acceptors, Org. Chem. 73 (2008) 1563-1566.

[33] J. Yu, Y. Shirota, A new class of high-performance red-fluorescent dyes for organic electroluminescent devices, [7-Diethylamino-3-(2-thienyl)chromen-2-ylidene]-2,2dicyanovinylamine and \{10-(2-Thienyl)-2,3,6,7-tetrahydro-1H,5H-chromeno [8,7,6-ij]quinolizin-11-ylidene\}-2,2-dicyanovinylamine, Chem. Lett. 31 (2002) 984-985.
[34] S.C. Lin, S.S. Sun, Amorphous 2, 3-substituted thiophenes: potential electroluminescent materials, Chem. Mater. 14 (2002) 1884-1890.

[35] (a) S. Destri, M. Pasini, C. Botta, W. Porzio, F. Bertini, L.J. Marchio, Synthesis and crystal structure and optical properties of fluorenic-core oligomers, Mater. Chem. 12 (2002) 924-933;

(b) M. Bera-Aberem, H.A. Ho, M. Leclerc, Functional polythiophenes as optical chemo-and biosensors, Tetrahedron 60 (2004) 11169-11173.

[36] G. Barbarella, M. Melucci, G. Sotgiu, The versatile thiophene: an overview of recent research on thiophene-based materials, Adv. Mater. 17 (2005) 1581-1593.

[37] D.J. Crouch, P.J. Skabara, M. Heeney, I. McCulloch, S.J. Coles, M.B. Hursthouse, Hexyl-substituted oligothiophenes with a central tetrafluorophenylene unit: crystal engineering of planar structures for p-type organic semiconductors, Chem. Commun. 11 (2005) 1465-1467.

[38] A. Facchetti, M.-H. Yoon, C.L. Stern, H.E. Katz, T.J. Marks, Building blocks for ntype organic electronics: regiochemically modulated inversion of majority carrier sign in perfluoroarene-modified polythiophene semiconductors, Angew. Chem. Int. Ed. 42 (2003) 3900-3903.

[39] G. Zhou, G. Qian, L. Ma, Y. Cheng, Z. Xie, L. Wang, X. Jing, F. Wang, Polyfluorenes with phosphonate groups in the side chains as chemosensors and electroluminescent materials, Macromolecules 38 (2005) 5416-5424.

[40] P. Wagner, A.M. Ballantyne, K.W. Jolley, D.L. Officer, Synthesis and characterization of novel styryl-substituted oligothienylenevinylenes, Tetrahedron 62 (2006) 2190-2199.

[41] J.P. Wuskell, D. Boudreau, M. Wei, L. Jin, R. Engl, R. Chebolu, A. Bullen, K. D. Hoffacker, J. Kerimo, L.B. Cohenb, M.R. Zochowski, L.M. Loewa, Synthesis, spectra, delivery and potentiometric responses of new styryl dyes with extended spectral ranges, J. Neurosci. Methods 151 (2006) 200-215.

[42] G. Ginocchietti, U. Mazzucato, A. Spalletti, Excited state behaviour of some thioanalogues of 1,3-distyrylbenzene, J. Photochem. Photobiol. A Chem. 196 (2008) 233-238.

[43] X. Yang, X. Jiang, Ch Zhao, R. Chen, P. Qina, L. Sun, Donor-acceptor molecules containing thiophene chromophore: synthesis, spectroscopic study and electrogenerated chemiluminescence, Tetrahedron Lett. 47 (2006) 4961-4964.

[44] Y.-S. Kim, S. Young-A, Synthesis of 2, 2-bithiophene based dye sensor and optical properties toward metal cations, Mol. Cryst. Liq. Cryst. 551 (2011) 163-171 (R.M. F).

[45] O.P. Klochko, I.A. Fedyunyayeva, S.U. Khabuseva, O.M. Semenova, E. A. Terpetschnig, L.D. Patsenker, Benzodipyrrolenine-based biscyanine dyes: synthesis, molecular structure and spectroscopic characterization, Dyes Pigments 85 (2010) 7-15.

[46] G. Grandolini, A. Martani, A. Fravolini, Benzobisthiazoles. VII. Synthesis and structure of benzobisthiazole isomers, Ann. Chim. 58 (1968) 1248-1267.

[47] S.P.G. Costa Batista, M. Belsley, C. Lodeiro, M.M.M. Raposo, Synthesis and characterization of novel (oligo)thienyl-imidazo-phenanthrolines as versatile pconjugated systems for several optical applications, Tetrahedron 64 (2008) 9230-9238.

[48] E. Fischer, Calculation of photostationary states in systems A-B when only A is known, J. Phys. Chem. 71 (1967) 3704-3710.

[49] O.J. Sandberg, M. Nyman, S. Dahlstrom, S. Sanden, B. Torngren, J.-H. Smatt, R. Osterbacka, On the validity of MIS-CELIV for mobility determination in organic thin-film devices, Appl. Phys. Lett. 110 (2017) 153504.

[50] A.L. Dubas, A.R. Tameev, A.I. Zvyagina, A.A. Ezhov, V.K. Ivanov, B. Konig, V. V. Arslanov, O.L. Gribkova, M.A. Kalinina, Ultrathin polydiacetylene-based synergetic composites with plasmon-enhanced photoelectric properties, ACS Appl. Mater. Interfaces 9 (2017) 43838-43845.

[51] B. Zhang, C. Qin, J. Ding, L. Chen, Z. Xie, Y. Cheng, L. Wang, High-Performance allpolymer white-light-emitting diodes using polyfluorene containing phosphonate groups as an efficient electron-injection layer, Adv. Funct. Mater. 20 (2010) 2951-2957.

[52] S.D. Tokarev, Yu A. Sotnikova, A.V. Anisimov, Yu V. Fedorov, G. Jonusauskas, D. A. Lypenko, V.V. Malov, A.R. Tameev, E.I. Maltsev, O.A. Fedorova, Donor-acceptor (E)-2-[2-(2,2'-bithiophen-5-yl)vinyl] benzo[d] thiazole: synthesis, optical, electrochemical studies and charge transport characteristics, Mendeleev Commun. 29 (2019) 567-569.

[53] Y. Gao, A. Pivrikas, B. Xu, Y. Liu, W. Xu, P.H.M. van Loosdrecht, W. Tian, Measuring electron and hole mobilities in organic systems: charge selective CELIV, Synth. Met. 203 (2015) 187-191.

[54] R.A. Irgashev, N.A. Kazin, N.I. Makarova, I.V. Dorogan, V.V. Malov, A.R. Tameev, G.L. Rusinov, A.V. Metelitsa, V.I. Minkin, V.N. Charushin, Synthesis and properties of new $\pi$-conjugated imidazole/carbazole structures, Dyes Pigments 141 (2017) $512-520$.

[55] J. Fang, B.H. Wallikewitz, F. Gao, G. Tu, C. Muller, G. Pace, R.H. Friend, W.T. S. Huck, Conjugated zwitterionic polyelectrolyte as the charge injection layer for high-performance polymer light-emitting diodes, J. Am. Chem. Soc. 133 (2011) 683-685.

[56] D.G. Georgiadou, M. Vasilopoulou, L.C. Palilis, I.D. Petsalakis, G. Theodorakopoulos, V. Constantoudis, S. Kennou, A. Karantonis, D. Dimotikali, P. Argitis, Conjugated zwitterionic polyelectrolyte as the charge injection layer for high-performance polymer light-emitting diodes, ACS Appl. Mater. Interfaces 5 (2013) 12346-12354.

[57] C.H. Yang, C.J. Bhongale, C.H. Chou, S.H. Yang, C.N. Lo, T.M. Chen, C.S. Hsu, Synthesis and light emitting properties of sulfide-containing polyfluorenes and their nanocomposites with CdSe nanocrystals: a simple process to suppress ketodefect, Polymer 48 (2007) 116-128 (Electron Supporting Information). 